\title{
Eastern Mediterranean Health Journal (EMHJ): a 20-year overview (1995-2014)
}

\author{
A. Mandil ${ }^{1}$, F. Curlet ${ }^{1}$, H. Nour El-Din ${ }^{7}$, N. Abu-Saleh ${ }^{7}$, M. A. Ahmed ${ }^{1}$
}

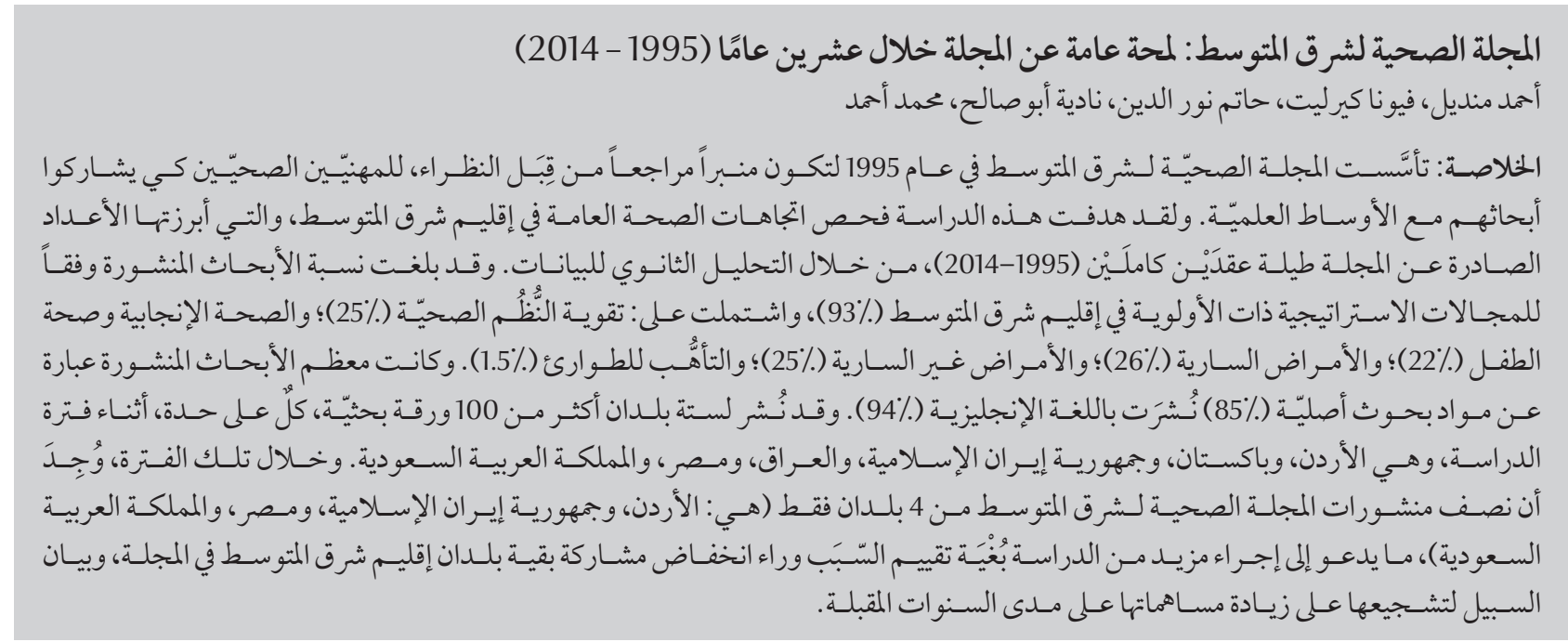

ABSTRACT The EMHJ was established in 1995 to provide a peer-reviewed platform for health professionals to share their research with the scientific community. The objective of this review was to examine EMR public health research trends, as reflected by EMHJ publications in 20 years (1995-2014), through secondary data analysis. Published articles were categorized according to EMR strategic priority areas (93\%), i.e. health systems strengthening (25\%); reproductive and child health (22\%); communicable diseases (26\%); noncommunicable diseases (25\%); emergency preparedness (1.5\%). Most papers were original research articles (85\%), published in English (94\%), but just over half (52\%) mentioned obtaining a form of ethical clearance in the text. Six countries had each over 100 papers published during the study period, i.e. Iran, Egypt, Saudi Arabia, Jordan, Iraq, Pakistan. HalfEMHJ publications during this period came from 4 countries only (Iran, Egypt, Saudi Arabia, Jordan), which calls for further study to evaluate why other EMR nations are less well represented and how to encourage greater contribution from them over the coming years.

\section{La Revue de la Santé dans la Méditerranée orientale : survol de 20 années (1995-2014)}

RÉSUMÉ La Revue de Santé de la Méditerranée orientale a été créée en 1995 afin de servir de plateforme avec examen collégial où les professionnels de la santé peuvent partager leurs travaux de recherche avec la communauté scientifique. L'objectif de la présente étude était d'examiner les tendances de recherche en santé publique dans la Région de la Méditerranée orientale, telles que reflétées par les publications de la Revue sur 20 ans (1995-2014), au moyen d'une analyse des données secondaires. Les articles publiés ont été catégorisés selon les domaines de priorités stratégiques de la Région de la Méditerranée orientale (93\%), à savoir le renforcement des systèmes de santé (25\%), la santé génésique et infantile (22\%), les maladies transmissibles (26\%), les maladies non transmissibles (25\%), et la préparation aux situations d'urgence (1,5\%). La plupart des publications étaient des articles de recherche originaux (85\%) publiés en anglais (94\%), mais seulement un peu plus de la moitié (52\%) ont mentionné avoir obtenu une forme d'approbation éthique dans le texte. Six pays ont publié plus de 100 articles chacun au cours de la période étudiée (Arabie saoudite, Égypte, République islamique d'Iran, Jordanie, Iraq, Pakistan). La moitié des publications de la Revue durant cette période ont été produites par quatre pays (I'Arabie saoudite, l'Égypte, la République islamique d'Iran et la Jordanie). Il serait donc intéressant d'étudier les raisons pour lesquelles d'autres pays de la Région de la Méditerranée orientale sont moins représentés, ainsi que la façon de les encourager à contribuer davantage dans les années à venir. 


\section{Introduction}

The Eastern Mediterranean Health Journal (EMHJ) is the flagship peer reviewed health periodical of the World Health Organization Regional Office for the Eastern Mediterranean (WHO/ EMRO) (1). EMHJ was established in 1995 primarily to provide a peerreviewed venue for public health researchers in the Eastern Mediterranean Region (EMR) to publish their research work at a time when there were only 70 health/biomedical journals published in Region (2). At the same time the Journal aimed to provide up-to-date information on (public) health developments with special reference to the Region and to allow health professionals to remain informed of developments in public health.

EMHJ publishes various types of solicited and unsolicited articles. These include unsolicited original research papers, reviews, reports, short communications, case reports, letters to the Editor, as well as solicited editorials, reviews, commentaries and reports of important regional meetings (3). In order to reach and be of relevance to a wide audience of health researchers and readers in the Region, EMHJ is available in both printed and electronic formats, and in keeping with the strategic objectives of WHO to make health knowledge accessible, all issues of EMHJ are freely accessible online at the EMHJ web pages (1). In addition, some 750 printed copies of each issue of EMHJ are distributed free of charge to ministries of health and to health and medical faculty libraries in the EMR countries, and there are more than 250 copies distributed worldwide through the WHO global subscriptions system. In addition, EMHJ publishes papers in Arabic, English and French (the 3 official WHO languages commonly used in the Region) and publishes the abstract of each paper in all three languages.
EMHJ endeavours to ensure that the papers it publishes conform to appropriate standards and best practices in research conduct and reporting. In that regard, EMHJ follows international guidelines for scholarly journals including the Recommendations for the Conduct, Reporting, Editing and Publication of Scholarly Work in Medical Journals (ICMJE Recommendations) and the Committee on Publication Ethics (COPE) and encourages authors to adhere to reporting guidelines such as: CONSORT (guidelines for reporting randomized trials); STROBE (guidelines for reporting observational studies); and PRISMA (Preferred Reporting Items for Systematic Reviews and Meta-Analyses), which are available at the EQUATOR Network (4).

$\mathrm{EMHJ}$ is included in numerous international and regional bibliographic databases and indexes, including MEDLINE/PubMed (5), the WHO Index Medicus for the Eastern Mediterranean Region (IMEMR) (6). EMHJ is now covered in the Thomson Reuters Science Citation Index Expanded and Social Sciences Citation Index and the Journal will start being assigned an impact factor in 2016 (7).

Submissions to EMHJ have increased steadily since 1995 up to 700 and its periodicity has risen from 2 issues in 1995 to 6 issues per year in 1999 and to 12 per year in 2010. EMHJ also produces special/theme issues and supplements, for example, on mental health, coronavirus and mass gatherings.

EMHJ has been in production now for over 20 years and has clearly grown in popularity and reputation. It serves all the countries of the Region and has published papers from every country of the Region, although some far more than others. Because of its regional reach, EMHJ can be considered a good resource for health research and heath researchers in the Region.

EMHJ's stated focus has always been public health with emphasis on the Region. However, at the time of its establishment, there were few medi$\mathrm{cal} /$ biomedical research journals in the Region. Therefore, in seeking to encourage health research in general, EMHJ's scope widened with papers being accepted and published of more clinical than public health relevance. However, since March 2013, guided by Dr Ala Alwan, EMHJ's Editor-in-Chief, the Journal has refocused on public health while continuing to improve its quality, relevance and reach (8).

While the numbers of papers submitted and accepted for publication in EMHJ have been tracked since its inception (Figure 1), there has been no systematic assessment of the types and focus of the research papers published in the Journal and whether these have changed over time, particularly in terms of the five WHO Strategic Health Priority Areas (SHPA): Strengthening of health systems; Maternal, reproductive and child health and nutrition; Noncommunicable diseases; Communicable diseases; and Emergency preparedness and response (8). Nor has there been an evaluation of the trends in submitting countries and the language of submissions. Such information would provide reflections on the research landscape in the Region related to public health.

This study was therefore conducted to: estimate the number of research papers published in relation to the five SHPA and country and language over 20 years of EMHJ's publication (1995-2014); determine the number of published papers that demonstrated adherence to the code of research ethics and obtained ethical approval and informed consent before the research was conducted (2011-2014).

\section{Methods}

\section{Study design and sample}

This was a secondary data analysis of articles published in EMHJ. The study included all published articles over 20 

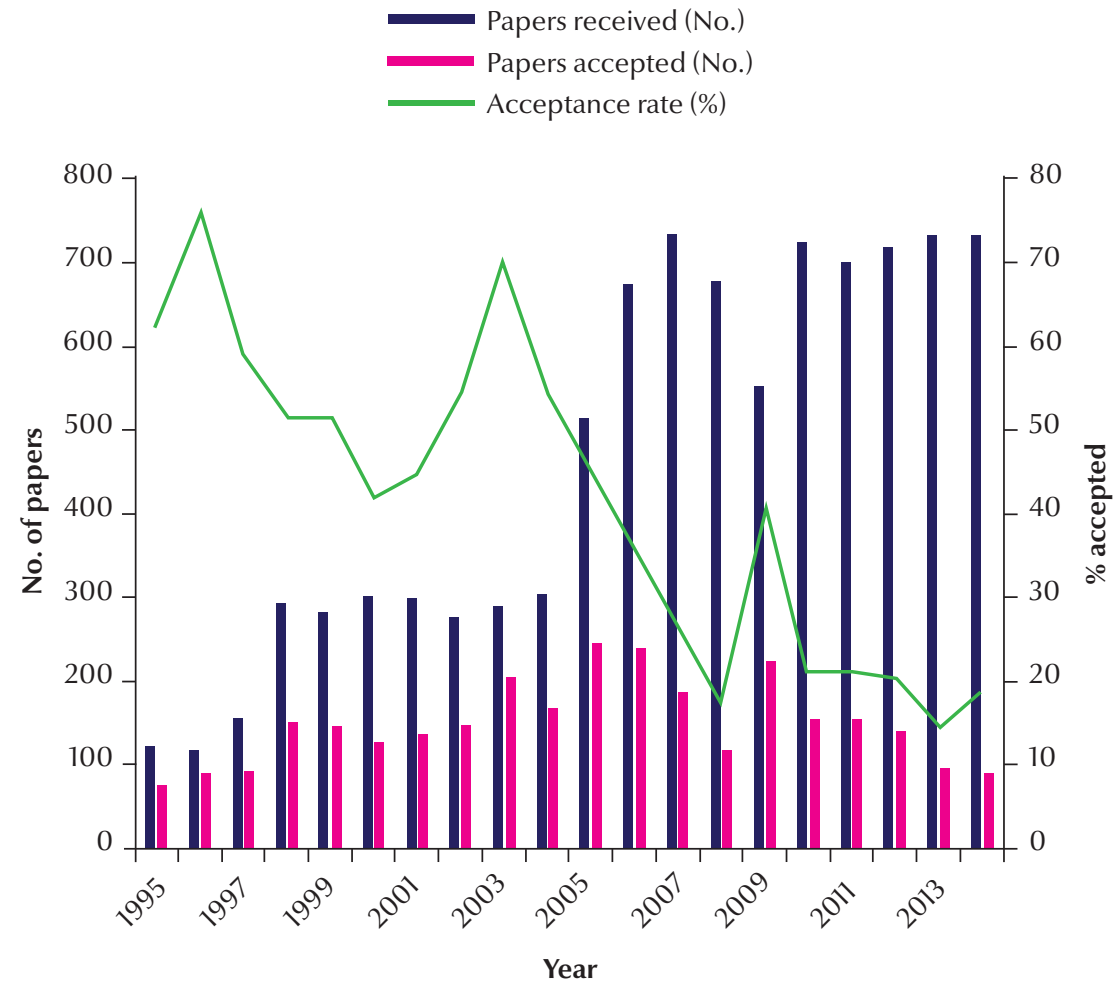

Figure 1 Papers submitted and accepted for publication in EMHJ, 1995-2014

years, i.e. between August 1995 and August 2014. For the analysis of adherence to research ethics standards, only papers published in the four years 2011-2014 were included. Although Cyprus was a Member State of the WHO Eastern Mediterranean Region until 2003 when it moved to the European Region, there were few papers from Cyprus published in EMHJ while it was an EMR Member State. It was decided therefore to include all published papers from Cyprus as non-EMR papers.

\section{Data sources}

The main data source for this review was the WHO Index Medicus for the Eastern Mediterranean (IMEMR), first launched in 1997 by the Regional Office $(6,9)$. The EMHJ publications indexed in IMEMR were used as a data source for this work. This sub-set was used for the data analyses outlined below.

\section{Classification by SHPA}

Although all EMHJ publications indexed in IMEMR were already classified according to the international standard classification scheme Medical Subject Headings (MeSH), US National Library of Medicine (NLM) (10), for the purposes of this study, EMHJ publications were reclassified according to the five EMR SHPA (11). Therefore, a list of sub-headings (MeSH terms) relevant to the SHPA were developed to be used as a standard scheme for the reclassification process; the complete list is shown in Appendix 1.

\section{Classification by ethical clearance}

Articles from 2011 to 2014 were scrutinized to determine if they reported that ethical approval for the study had been obtained. Papers that reported ethical clearance had been obtained were sub-categorized according to whether they had obtained full ethical clearance (from an Institutional review board or ethics review committee) or partial approval through participants' informed consent (verbal/written). Articles that did not mention any ethical clearance were sub-categorized into two categories: those that needed ethical clearance and those that did not need ethical approval. Articles that were not considered to need ethical clearance were: reviews, editorials, clinical guidelines, commentaries, letters to the Editor, secondary data analyses, and case reports \& series.

\section{Results}

Over 20 years of publication, 2704 articles were published in EMHJ, the majority of which were from EMR countries (76\%) (Table 1). The majority of the papers published were research articles (2287) followed by reviews (113) and case reports (89). In terms of the five SHPAs, over $90 \%$ of the articles were related to these for both EMR and non-EMR countries. With regards to language, Table 2 shows that the vast majority of papers published in EMHJ were in English (94\%), with only $4 \%$ in French and 2\% in Arabic.

\section{SHPA and country analysis}

Figure 2 shows that all countries of the Region have had papers published in EMHJ. The leading 4 countries are the Islamic Republic of Iran $(414,20 \%)$, followed by Egypt (264, 13\%), Saudi Arabia (221, 11\%) and Jordan (134, 6\%). In addition, 180 (9\%) papers were multi-centre studies from morethan one EMR country. Figures 3 and 4 reflect publications from the Region indexed in the Index Medicus for the Eastern Mediterranean Region (IMEMR) and NLM PubMed, consecutively. It is to be noted that the leading 3 countries, i.e. Iran, Egypt and Pakistan, were the same in both search engines.

The EMR country data were broken down in 5-year intervals to show the trend over time of published articles for the countries (Figure 5). It shows that the number of papers from Iran increased considerably from 2000 to 2004 and it became the leading country 


\section{Appendix (1)}

WHO/EMRO Five Strategic Health Priority Area (SHPA) Classification Scheme (The list has been developed by the WHO/EMRO Library staff in order to categorize the major MeSH terms with the five WHO SHPA to be used for classification purpose)

\section{1 - Communicable Diseases}

- Acquired Immunodeficiency Syndrome - AIDS

- Blood Safety

- Cholera

- Communicable Disease Control

- Epidemic Diseases

- Epidemiology

- Health Regulations

- Human Immunodeficiency Virus - HIV

- Immunization

- Laboratories

- Leprosy

- Lymphatic Filariasis

- Malaria

- Measles

- Pandemic Diseases

- Poliomyelitis

- Rubella

- Sexually Transmitted Diseases - STD

- Tropical Diseases

- Tuberculosis

- Vaccines

- Zoonoses

\section{2 - Emergency and Humanitarian} Action

- Accident Prevention

- Disasters

- Emergency Preparedness

- Epidemiology

- Health Research

- Health Surveys

- Human Rights

- Road Safety

- Statistics

\section{3 - Maternal and Child Health and} Nutrition

- Adolescent Health

- Child Health

- Epidemiology

- Gender Issues

- Health Education

- Health Protection and Promotion

- Health Research

- Health Surveys

- Human Rights

- Maternal Health

- Nutrition

- Reproductive Health
- Social Determinants

- Statistics

- Violence

- Women's Health

04 - Health System Development

- Community Health

- Epidemiology

- Essential Medicines

- Health and Biomedical Devices

- Health Economics

- Health Financing

- Health Manpower

- Health Planning

- Health Policy

- Health Research

- Health Surveys

- Hospital Care

- Human Rights

- Midwifery

- Nursing

- Patient Safety

- Pharmaceutical Policies

- Professional Education

- Statistics

05 - Noncommunicable and Chronic Diseases

- Alzheimer Disease

- Blindness

- Cardiovascular Diseases

- Diabetes

- Disability and Rehabilitation

- Epidemiology

- Epilepsy

- Food Safety

- Health of the Elderly

- Health Research

- Health Surveys

- Hearing Loss

- Human Rights

- Hypertension

- Mental Health

- Neoplasms

- Oral Health

- Physical Activity

- Smoking

- Statistics

- Substance Abuse

- Tobacco

- Wounds and Injuries with papers published in the EMHJ, and even more so from 2005 to 2009.

Figure 6 shows the distribution of EMHJ published papers in EMR countries by the five WHO SHPA (n $=1964)(72.6 \%)$. The proportions of published papers were similar for 4 of the SHPA: communicable diseases (26.2\%), noncommunicable diseases (25.8\%), health system strengthening (24.5\%) and maternal, reproductive and child health and nutrition (22.0\%). However, very few papers published related to emergency preparedness and response (1.5\%). This was similar for both EMR and non-EMR countries, with almost equal numbers of papers published for all priority areas except emergency preparedness and response.

Figure 7 shows the trend in papers published in EMHJ by the five SHPA categorized in 5-year intervals. In the five years 2010-2014, there has been some increase in papers published on communicable diseases $(n=248)$, noncommunicable $(n=213)$ and health system development $(n=209)$. There was a decrease in papers on maternal, child health and nutrition $(n=173)$ in this period compared with the period 2005-2009 $(n=197)$. There was a slight increase in papers on emergency and humanitarian during the period 2010-2014 $(n=17)$ compared with 2005-2009 $(n=10)$.

Looking at distribution of published papers related to each of the SHPA by EMR country during the 20 year period (1995-2014) shows that Iran ranked first for all SHPA with Saudi Arabia ranked second for noncommunicable diseases, health systems, and emergency preparedness and response; it ranked seventh for communicable diseases. Egypt ranked second for papers related to communicable diseases and maternal, reproductive and child health and nutrition. Iraq $(42,8.2 \%)$ and Sudan $(39,7.6 \%)$ ranked third and fourth for communicable disease-related papers. Only 7 of the 22 member countries had published papers related to emergency 


$\begin{aligned} & \text { Table 1 Papers published in EMHJ (1995-2014) by EMR/non-EMR country and the 5 EMR Strategic Health Priority Areas } \\
& \text { (SHPA) }\end{aligned}$
\begin{tabular}{lccc} 
& & \\
EMHJ papers & Total no. of papers & EMR countries & Non-EMR countries \\
EMHJ papers by EMR/non-EMR country & 2704 & 2097 & 607 \\
EMHJ papers by the five SHPA & $2521(93 \%)$ & $1964(94 \%)$ & $557(92 \%)$ \\
\hline
\end{tabular}

\begin{tabular}{lc}
\hline Table 2: Papers published in EMHJ (1995-2014) by language of paper $(\boldsymbol{n}=\mathbf{2 7 0 4})$ & \\
\hline Language & Total no. of EMHJ papers $(\boldsymbol{n}=\mathbf{2 7 0 4})$ \\
Arabic & $57(2 \%)$ \\
English & $2542(94 \%)$ \\
French & $105(4 \%)$ \\
\hline
\end{tabular}

preparedness and response: Iran and Saudi Arabia with 7 papers each, followed by Pakistan with 5 and Bahrain with 2; there were also 5 papers that emanated from multicentre collaborations.

\section{Ethical clearance analysis}

Table 3 shows the ethical clearance status of articles published in EMHJ between 2011 and 2014. Just over half of the articles (52.0\%) had obtained some form of ethical approval. Of these, 251 papers $(71.1 \%)$ were fully approved by an institutional review board or ethical review committee, while 100 (28.5\%) had partial approval by informed consent (verbal or written) from the study participant. However 324 (48\%) did not report any ethical approval, a situation which is no more existent by new measures in place by EMHJ which requires prior ethical clearance of carrying out the study, for the article to be considered by publication. $\mathrm{Nev}$ ertheless, reviewers were expected to look into ethical aspects of conducted research, even before this provision was enacted. Of these articles, 81 (25\%) were research studies on human participants which require ethical clearance, while the majority (75\%) were articles and research that did not involve any human participants or did not need ethical clearance.

\section{Discussion}

\section{Trend of number of papers submitted and published over 20 years}

As reported in Figure 1, the number of articles submitted to EMHJ has increased considerably in the 20 years of publication indicating the growing popularity of the Journal; this reached a high of 718 papers in 2012. In the past two years the number of papers submitted has declined slightly, possibly due

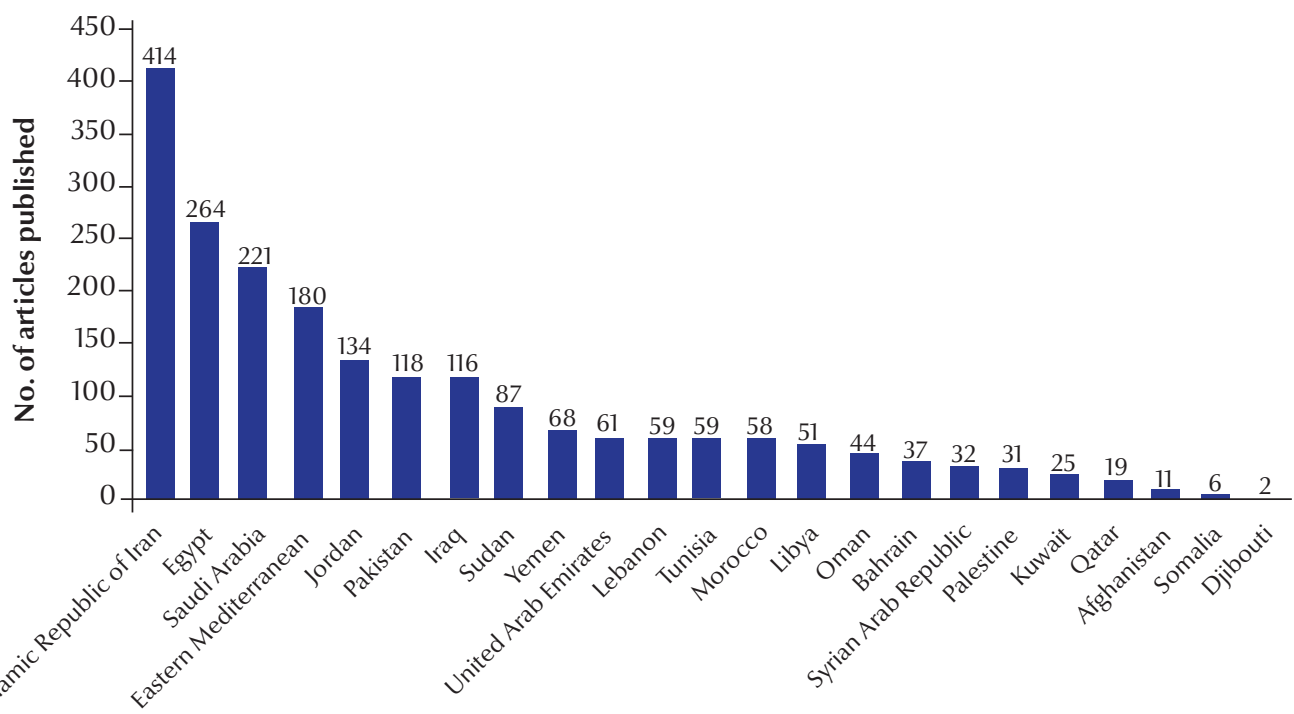

Figure 2 Articles published in EMHJ, by EMR country of research, 1995-2014 $(n=2097)$ 


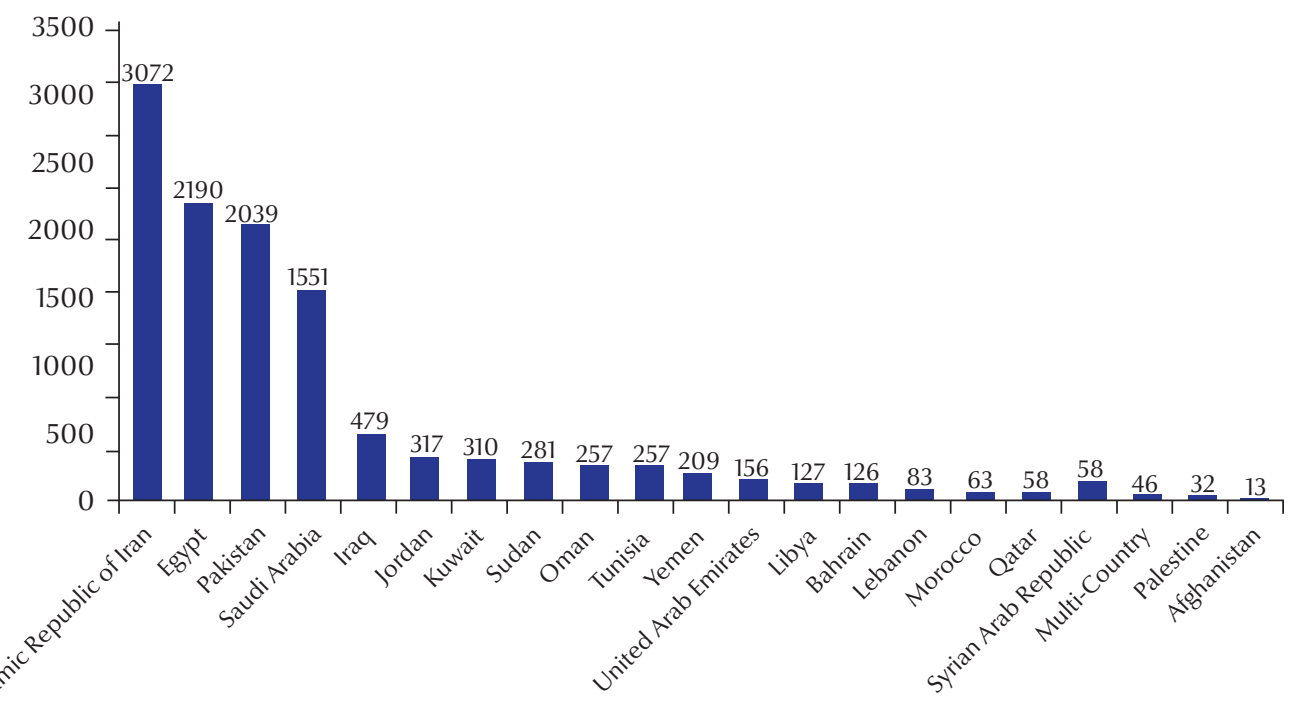

to the more stringent criteria of quality and public health relevance being applied. The acceptance rate has varied having reached a high of $89 \%$ in 1996 ; in 2014 it was $17.9 \%$, which reflects the more rigorous acceptance criteria now in place.

The clear predominance of English as the language of the papers published, with very few in Arabic and French, may reflect the perception of authors that their paper will reach a wider audience and have more impact if published in English or that EMHJ is biased to publishing in English. EMHJ does not publish in non-UN languages such as Farsi or Urdu, which are the languages of the Islamic Republic of Iran and Pakistan respectively, two of the countries with the most papers published; authors from these countries have no option therefore but to submit in English. At the same time, in a majority of countries of the Region, medicine and biomedical sciences are taught in English in university and authors may feel more

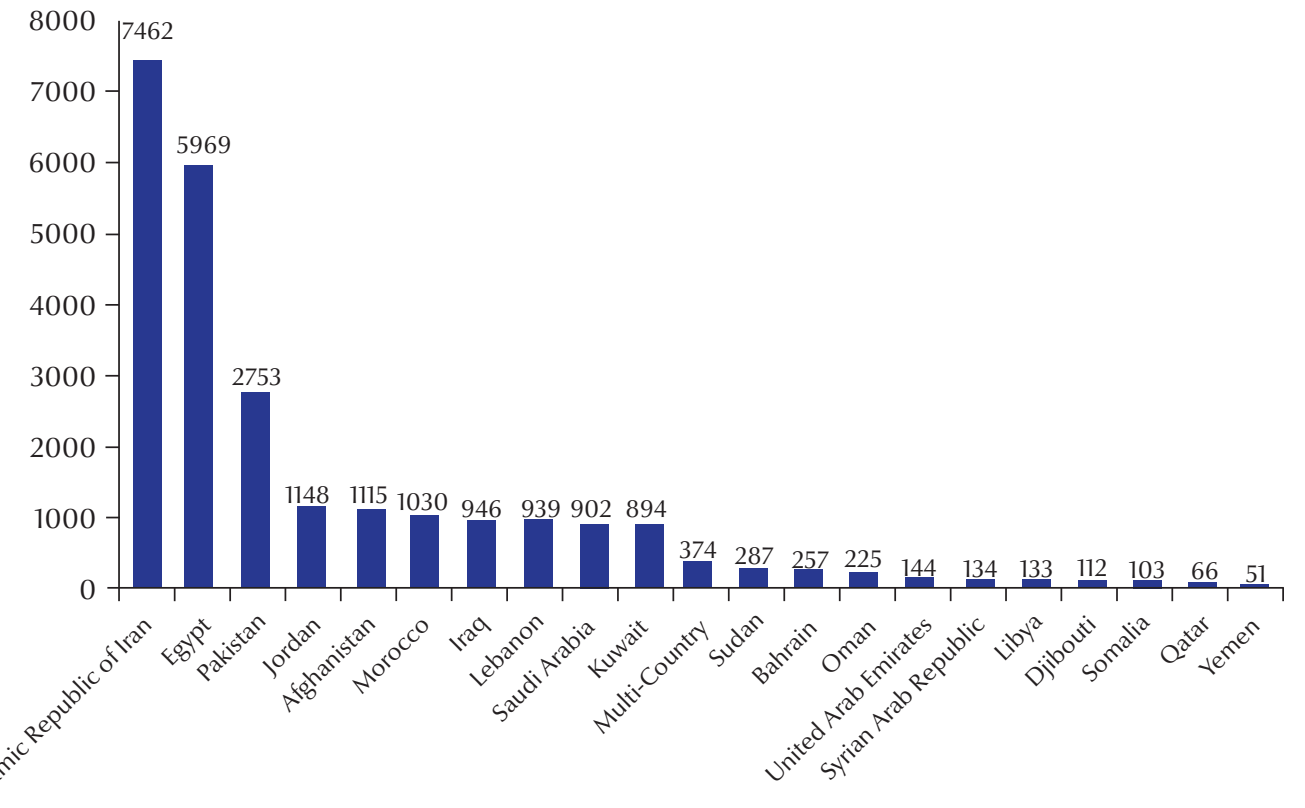




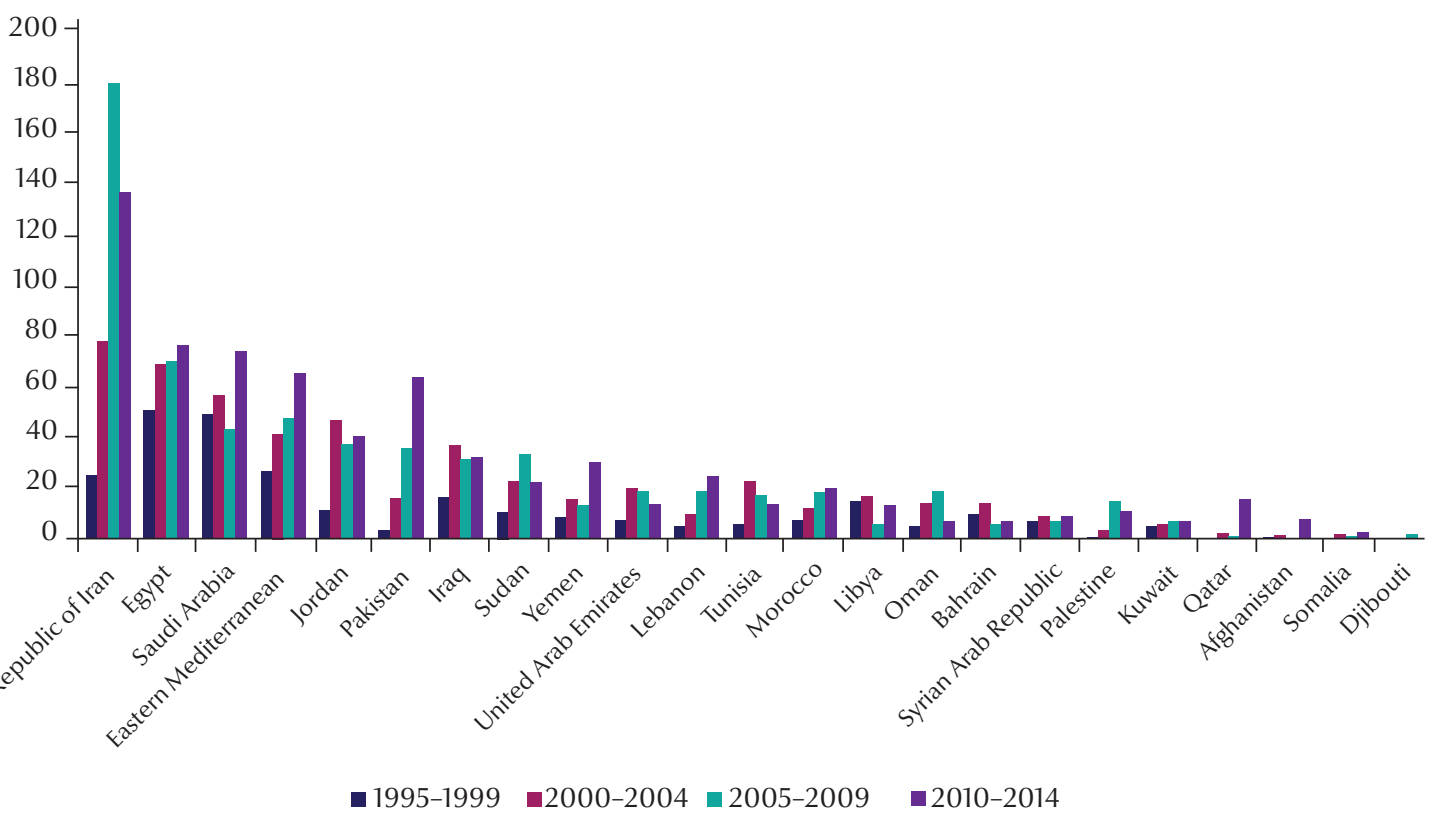

Figure 5 EMHJ Papers published in 5-year intervals (1995-2014), by EMR country of research $(n=2097)$

comfortable therefore writing their paper in English.

\section{Comparison of published articles, by SHPA}

Over the 20-year period of publication of EMHJ the vast majority of papers published, whether from within or outside

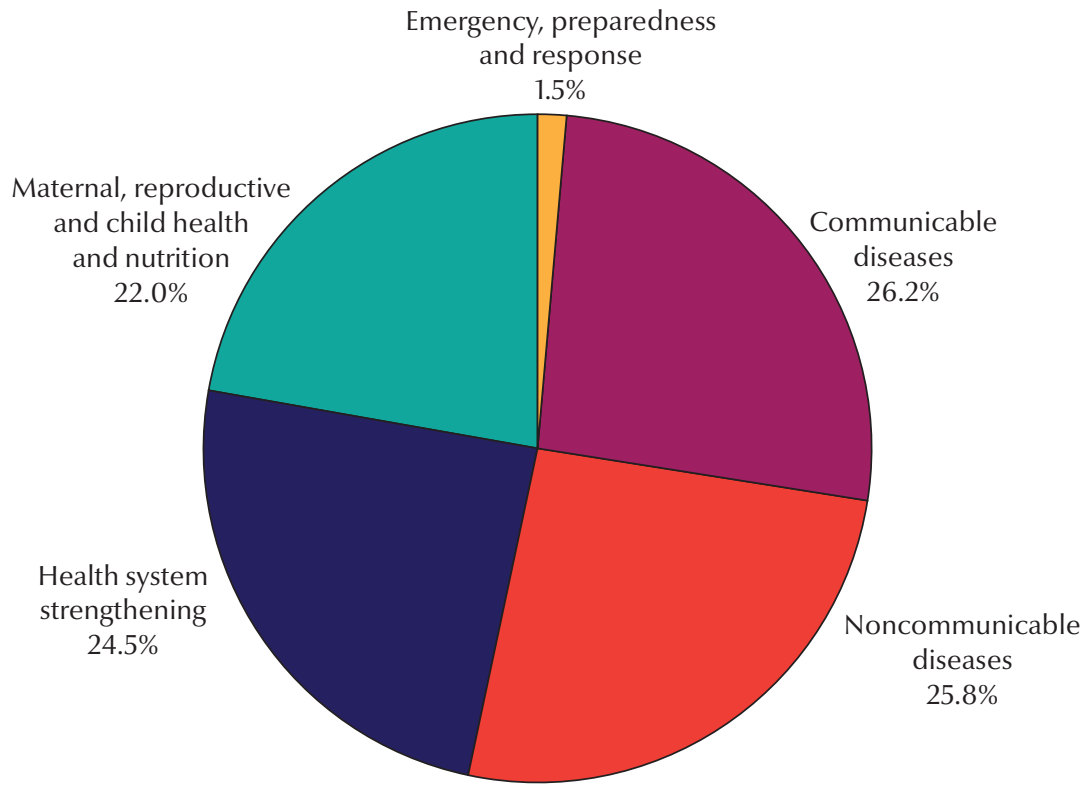

Figure 6 Distribution of EMHJ Papers by WHO/EMRO five SHPA, 1995-2014 ( $n=1964)$ the Region, were related to the five EMR SPHA (93\%). Communicable diseases, noncommunicable diseases and health systems strengthening were the focus of roughly the same number of papers. Maternal, reproductive and behind. However, most obviously, very child health and nutrition fell slightly

few of the papers published were related to emergency preparedness and response. This is surprising given the fact that many countries of the Region have experienced emergencies, both natural and manmade, in the past 20 years; for example in Palestine, Afghanistan, Iraq, Syrian Arab Republic, Lebanon, Pakistan and the Islamic Republic of Iran, several of which continue to suffer from ongoing humanitarian emergencies. Within the 5-year period 1995-1999, marginally fewer papers were concerned with communicable diseases than noncommunicable diseases, maternal, reproductive and child health and nutrition and health systems strengthening but for 2010-2014, communicable diseases ranked first, possibly due to the emergence of $\mathrm{H} 1 \mathrm{~N} 1$, MERS-CoV and other new pathogens that have emerged in recent years igniting public health interest and concern in infectious diseases and their potential global spread.

\section{Top 5 countries' published}

Six countries have each over 100 papers published in the 20-year period: the Islamic Republic of Iran, Egypt, Saudi 
Arabia, Jordan, Iraq and Pakistan. With the exception of Pakistan, these countries have been in the top 6 within each 5-year timespan, although the rankings have changed between them. The dominance of these six countries while others were rarely represented may be because the lower published countries tended to be smaller and/or less well resourced (output has to be always linked to input [institutions, researchers, funding, etc.] ) or those having experienced/ experiencing emergencies which would undermine their ability to conduct and publish research. In the period 1995-1999, Egypt and Saudi Arabia had the largest number of papers published but in 2000-2004 and then again in 2005-2009, there was a considerable increase in the papers published from Iran which became the leading country with papers published in EMHJ. While the number of papers published from Iran dropped for the period 2010-2014, it remains the top country for the number of papers published. The significant increase in Iran's research output has been attributed to a policy change in the country to increase the research budget for the health sector, an increase in health faculty members and an increase in biomedical research centres (12). Pakistan showed a clear increase in each time period and for 2010-2014 overtook Jordan; this may indicate its overall increase in research output in medicine over time (13). Both countries have been known to provide excellent resources for health research, which is reflected in their research output and publications.

\section{Top 5 countries published for each SPHA}

For all the SPHA, the Islamic Republic of Iran had the greatest number of published papers, due to their overall high number of published papers, although the highest number of $\mathrm{pa}-$ pers overall from Iran were related to communicable diseases. Similarly for
Egypt, communicable diseases were the focus of the largest number of papers although closely followed by noncommunicable diseases, while for Jordan maternal, reproductive and child health and nutrition was the health topic most papers published and noncommunicable diseases the least, after emergency preparedness and response. Noncommunicable diseases were the focus of the largest number of the papers from Saudi Arabia with communicable diseases having the lowest number after emergency preparedness and response (EPR); in fact Saudi Arabia fell to fifth and sixth place respectively for maternal, reproductive and child health and nutrition and communicable diseases. This may reflect the epidemiological transition and the growing burden of noncommunicable diseases in the country. At the same time, Sudan and Yemen were among the top 5 countries publishing papers related to communicable diseases, perhaps reflecting the burden of these diseases in their countries. Interestingly, Saudi Arabia and Iran had the greatest number of published papers related to emergency preparedness and response (7 each).

With respect to published articles on EPR during the study period (19952014), it was noted that such articles mainly came from Pakistan (8), Saudi Arabia (7), Iran (6) with some articles of EMR nature (6); two each from Bahrain, Egypt, UAE; and one each from: Jordan, Morocco, Tunisia, Qatar, and Yemen. Seven were published during 1995-1999; four during 2000-2004; nine during 2005-2009 and 16 during 2010-2014. More than half published EPR articles were on injuries (20) of which half $(10)$ were related to roadtraffic injuries; followed by emergency health services (5); one each on water floods, earthquakes, cyclones and other emergency-related topics.

\section{Article type}

A very large majority of papers published in EMHJ from 1995 to 2014 were original articles, which is in line with the objectives of the journal to publish and publicise quality health research and information with emphasis on public health and to provide evidence to inform the development of public health policies and programmes. Few clinical trials were published, possibly reflecting the paucity of such studies being conducted in the Region, or that authors may seek to publish in more international than regional forums or that the quality/rigour was not found high enough for acceptance. EMHJ has for some time required clinical trials to be registered in a Primary Registry in the WHO Registry Network (14)as a condition for consideration for publication of the results and now requires adherence to the CONSORT guidelines and checklist (4), and will be requiring papers reporting systematic reviews/ meta-analysis and observational studies to follow the relevant guidelines (4).

\section{Ethical clearance}

Of some concern is that around $25 \%$ of the papers published in EMHJ over the 20 years did not specify whether ethical issues had been considered in terms of obtaining institutional review board clearance for the study or obtaining informed consent from participants. Efforts have been made in the Journal to be more rigorous in ensuring ethical issues are addressed and stated. EMHJ now clearly outlines in its Guidelines for Authors (15) and in its recently published Guidelines on Ethical Conduct and Publication of Health Research (16), the ethical standards it requires authors to adhere to in the conduct of research on which they are submitting a paper. These are based on the many resources that address the ethical issues related to research involving humans. However the trend over time for compliance with ethical standards was not examined to 


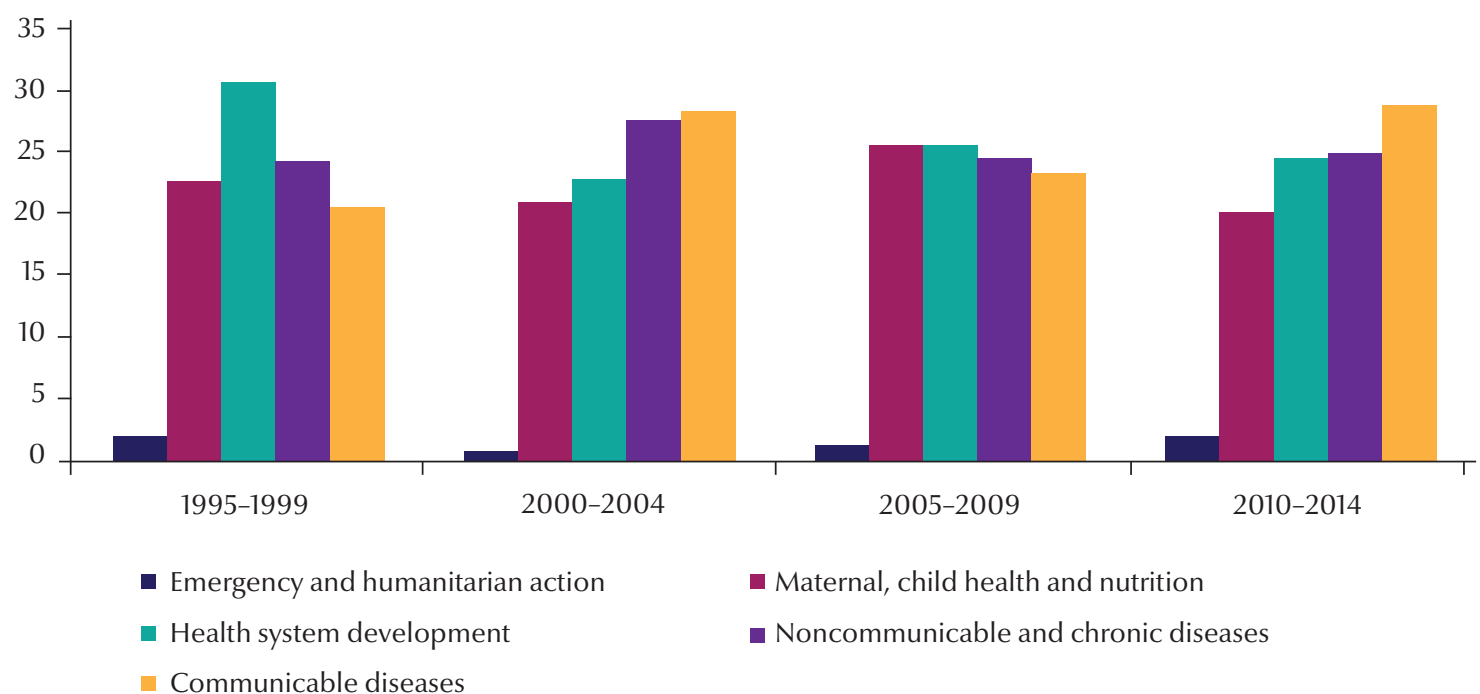

Figure 7 Distribution of papers published in EMHJ in 5-year intervals by EMR strategic health priority area, 1995-2014 $(n=2704)$

know whether the situation has improved.

\section{Conclusion and recommendations}

This review of EMHJ over 20 years examined only the papers published in $\mathrm{EMHJ}$ and not those that were not accepted for publication and so the country data, relevance to the health priority areas and ethical compliance for these submissions was not been assessed. This latter group constitutes a greater number than those published and they may show a different picture; perhaps they were less ethically compliant and less related to the health priority areas, which may partially explain why they were not considered for publication. Nonetheless, the paper reflects on health areas covered in EMHJ publications, which countries were the dominant producers during the study period. In view of this, the following are recommended.

1. In line with EMHJ's mission, continue to focus on publishing public health focused research related the SPHA, especially in the area of emergency preparedness and response, ensuring policy implications are highlighted;

2. Encourage and motivate the countries with low numbers of scientific research publications, with special focus on capacity building in research methods, ethics and scientific writing.

3. Assess the implications of the dominance of English as the language of papers published in EMHJ, particularly in relation to disseminating policy implications.

\begin{tabular}{llccc}
\hline \multicolumn{2}{l}{ Table 3 Ethical clearance of papers published in EMHJ, 2011-2014 $(\boldsymbol{n = 6 7 5 )}$} & & & \\
\hline Category & \multicolumn{1}{c}{ Sub group } & Number & \% from the same group & \% from total \\
Obtained ethical clearance & Full: approval from (IRB-ERC-REC) & 251 & 71.5 & 38.3 \\
& Partial: informed consent (written/verbal) & 100 & 28.5 & 15.2 \\
& Sub-total & 351 & - & 52.0 \\
Did not obtain clearance & Needed & 81 & 25.0 & 12.0 \\
& Not needed* & 243 & 75.0 & 36.0 \\
& Sub-total & 324 & - & 48.0 \\
Total & & 675 & - & - \\
\hline
\end{tabular}

*Reviews, editorials, clinical guidelines, communications, letters to the Editor, secondary data analyses, case reports \& series; IRB: institutional review board; ERC: ethical review committee; REC: research ethics committee. 


\section{References}

1. World Health Organization, Regional Office for the Eastern Mediterranean. Eastern Mediterranean Health Journal [webpage] (http://www.emro.who.int/emh-journal/eastern-mediterranean-health-journal/home.html, accessed 1 May 2016).

2. Al-Shorbaji N. Index medicus for the Eastern Mediterranean region. Emerg Themes Epidemiol. 200809 30;5:14. PMID:18826568

3. U.S. National Library of Medicine. Publication Characteristics (Publication Types) - Scope Notes. Medical Subject Headings [webpage]. (https://www.nlm.nih.gov/mesh/pubtypes.html, accessed 1 May 2016).

4. EQUATOR Network. Enhancing the QUAlity and Transparency Of health Research [website] (http://www.equator-network. org/, accessed 1 May 2016).

5. US National Library of Medicine. PubMed. [website] (http:// www.ncbi.nlm.nih.gov/pubmed/, accessed 1 May 2016).

6. World Health Organization, Regional Office of the Eastern Mediterranean. Index Medicus for the Eastern Mediterranean Region (IMEMR) [webpage] (http://www.emro.who.int/information-resources/imemr/imemr.html, accessed 1 May 2016).

7. Thomson Reuters. Web of Science [website] (http://thomsonreuters.com/en/products-services/scholarly-scientificresearch/scholarly-search-and-discovery/web-of-science. $\mathrm{html}$, accessed 1 May 2016).

8. Shaping the future of health in the WHO Eastern Mediterranean Region: reinforcing the role of WHO. Cairo: World Health Organization. Regional Office for the Eastern Mediterranean; 2012.

9. World Health Organization, Regional Office for the Eastern Mediterranean. Index Medicus for the Eastern Mediterranean Region (IMEMR) [webpage] (http://applications.emro. who.int/library/Databases/wxis.exe/Library/Databases/ $\mathrm{iah} /$ ? IsisScript=iah/iah.xis\&lang=I\&base=imemr, accessed 1 May 2016).
10. Medical Subject Headings (MeSH). U.S. National Library of Medicine (NLM). [Online] 1999. [Cited: 22 October 2015.$]$ https://www.nlm.nih.gov/mesh/MBrowser.html

11. World Health Organization, Regional Office for the Eastern Mediterranean. Strategic directions [webpage] (http://www. emro.who.int/about-who/strategic-directions/, accessed 1 May 2016).

12. Samadikuchaksaraei A, Mousavizadeh K. High-tech biomedical research: lessons from Iran's experience. Biomed Eng Online. 200805 23;7:17. http://www.biomedical-engineering-online.com/content/7/1/17 PMID:18501001

13. SCJ. Scimago Journal \& Country Rank. Pakistan [webpage] (http://www.scimagojr.com/countrysearch. php?area=2700\&country=PK\&w, accessed 1 May 2016).

14. World Health Organization. International Clinical Trials Registry Platform (ICTRP) (http://www.who.int/ictrp/network/en/, accessed 1 May 2016).

15. Eastern Mediterranean Health Journal. Guidelines for authors (http://www.emro.who.int/images/stories/emhj/documents/guidelines_for_authors.pdf?ua=1, accessed 1 May 2016).

16. Eastern Mediterranean Health Journal. EMHJ Guidelines on Ethical Conduct and Publication of Health Research (http:// www.emro.who.int/emh-journal/authors/emhj-guidelineson-ethical-conduct-and-publication-of-health-research.html, accessed 1 May 2016).

17. Alwan A. Filling the gap: restoring EMHJ's public health identity. East Mediterr Health J. 2014 06 18;20(6):359.http://www. emro.who.int/emhj-vol-20-2014/volume-20-6/from-theeditor-in-chief-filling-the-sap-restoring-emhjs-public-healthidenti.html PMID:24960510 